\title{
¿Es posible abatir la pobreza en el capitalismo?
}

\author{
Aquiles Montoya
}

\section{Resumen}

La pobreza ha sido una constante en el devenir de los tiempos. El advenimiento del capitalismo no sólo la ha mantenido sino que ha incrementado los niveles de la misma. Este artículo analiza las raíces de la pobreza, los planteamientos erróneos que se han empleado para erradicarla, así como los diversos programas de los gobiernos para combatirla, etc. Finalmente, el autor presenta una propuesta que, entre sus características, no propone un cambio de sistema, no afecta a los empresarios, respeta la propiedad privada y no hay reformas radicales.

\section{Introducción}

La preocupación por acabar con la pobreza ha sido una constante entre diferentes economistas $y$, particularmente, entre los teóricos del desarrollo, quienes adquirieron tal perspectiva debido a los acelerados niveles de crecimiento de la industria y a la aparente posibilidad de que con el capitalismo la humanidad avanzaría por fin hacia el reino de la abundancia de satisfactores materiales.'Sin embargo, la problemática de la pobreza no sólo se mantiene con el advenimiento y desarrollo del capitalismo sino que permuta las causas que la generaron en el pasado, preserva algunas de sus manifes- taciones y simultáneamente crea nuevas maneras de vivir y sufrir la pobreza.

Dada la longevidad de la pobreza, es preciso tener algún cuidado y realizar las precisiones neceşarias que permitan diferenciar la pobreza de hoy en día de la pobreza de los regímenes anteriores. Así, por ejemplo, la pobreza por carencia que se padecía en los sistemas feudal y esclavista, previos al capitalismo, era de naturaleza muy distinta de la que se padece en la actualidad. Ahora existen pobres en medio de la abundancia de satisfactores. No es que no existan medios de vida suficientes para saciar las necesidades de las personas, sino 
que los pobres carecen de los medios monetarios para adquirirlos.

Antiguamente, el incipiente desarrollo de la ciencia y la tecnología limitaba la productividad del trabajo y generaba, en parte, pobreza. Ahora, el desmedido desarrollo de la productividad del trabajo hace que muchas personas se encuentren en condición de pobreza al ser innecesarios para el capital y, en consecuencia, no tienen acceso a ningún trabajo, ni a una remuneración por el mismo, lo cual les impide participar en la distribución de lo producido, por ello se hunden irremediablemente en la más abyecta miseria, a pesar de contar con capacidad y necesidad de trabajar.

Por otra parte, en el sistema esclavista, el amo tenía interés en que el esclavo no muriera, de allí que buscara proporcionarle los cuidados necesarios para mantenerlo sano y salvo, algo así como lo que ocurre en la actualidad con los animales domésticos - perros, gatos, garrobos- y otros menos domesticados. Sin embargo, al empresario capitalista poco le importa cómo vivan los trabajadores, su única preocupación, si acaso tienen alguna relacionada con la vida de los trabajadores, se reduce a que en todo momento existan los obreros necesarios para no detener los procesos de producción y circulación. La preocupación por preservarse sano y salvo es exclusiva del trabajador.

Las razones por las cuales los esclavos vivían en la pobreza son muy diferentes de aquellas por las cuales se encuentran en la pobreza los obreros de hoy en día. De modo que aunque la pobreza siempre ha existido, no es de la misma naturaleza, como no lo son tampoco las causas que la generan en los distintos regímenes sociales.

La pobreza tiene un carácter histórico que es preciso desentrañar en cada momento, a fin de poder pensar en alternativas posibles para su resolución en el caso particular o específico que nos ocupe. Las generalidades como las generalizaciones a menudo no brindan los resultados esperados. Así, quienes afirman sin más que la pobreza siempre ha existido y que por ende siempre existirá, no entienden que el capitalismo genera su propia pobreza y de entrada niegan la posibilidad de buscar alternativas reales de solución para la misma.

La pobreza es un mal mundial -más de dos tercios de los habitantes del planeta viven en la pobreza-, por tanto, las propuestas para abatirla son múltiples y variadas. Pese a todo, la pobreza todavía constituye un fenómeno secular de solución aparentemente imposible. Ello es así por la misma forma en que tradicionalmente se ha abordado o planteado el problema. Para iniciar es preciso reconocer y aceptar sin mayores dificultades que el sistema genera pobreza y que, por tanto, resulta ilusorio creer que el simple crecimiento económico conducirá por sí mismo a la eliminación de la pobreza. Al parecer, éste ha sido el principal problema que han enfrentado tanto los teóricos del desarrollo, como las distintas agencias que se han ocupado de combatir la pobreza a nivel mundial. Amén de aquellos que nunca han buscado enfrentar la pobreza y que más bien han estado interesados en servirse de la misma.

No es posible encontrar soluciones para erradicar la pobreza, en tanto y en cuanto se recete a los países y sus pueblos capitalismo y más capitalismo. Seguro que la homeopatía que no se aplica al problema de la pobreza. La tendencia a replicar los procesos que siguieron los países hoy desarrollados ha sido una constante en la historia de las teorías del desarrollo, como lo es en la actualidad la necia y contumaz política de transformación de los "informales" y/o microempresarios en empresarios capitalistas. Ya no digamos todas las prácticas asistencialistas, paternalistas e inmovilizantes acatadas por los gobiernos nacionales a instancias de los organismos internacionales, que han sido revestidas por una fraseología equívoca y que han prostituido incluso términos propios del desarrollo auténtico, como participación, cooperación, solidaridad, articulación sectorial, etc.

En cambio, si se reconoce como punto de partida que la pobreza surge por obra y gracia del sistema capitalista y que se desarrolla al atender a las mismas leyes que gobiernan el funcionamiento de las empresas y el capital, se conocerán las causas de la misma y también los límites que existen para su resolución en el interior del sistema capitalista. Sólo así se podrán considerar posibles alternativas teóricas que constituyan auténticas salidas a la pobreza y la marginación social.

Al hablar de pobreza implícitamente se involucra también a la riqueza, y de ésta última es preciso efectuar algunos señalamientos con el fin de evitar las tradicionales necedades de quienes se ocupan de éste y cualquier otro tema, sin tener la formación mínima que les permita opinar con un mínimo de lucidez. Así, hablar de riqueza en general resulta muy impreciso porque, ¿qué es rique- 
za? Para cualquiera imbuido de las ideas capitalistas, la riqueza es el dinero, ya que ésta es la forma más abstracta de la riqueza en el capitalismo; sin embargo, ello es así y sólo así en una sociedad mercantil. Para una tribu perdida del Amazonas, un manojo de billetes - aunque sean dólares - no representa ninguna riqueza. Pero, seguramente los indígenas sí considerarían como riqueza un puñado de frutas silvestres o granos cultivados que formen parte de su dieta alimenticia.

La noción de riqueza varía conforme a la realidad social en la que el individuo se desenvuelve, así como también "aqueIlo" que la genera. En una sociedad capitalista, la riqueza se atribuye a todo lo que tiene un valor y por consiguiente se expresa en un precio, o sea, pues, que es apreciado en términos monetarios. Esta riqueza es generada por el trabajo y puede establecerse en última instancia la magnitud de su valor por las horas de trabajo socialmente necesario que contenga el objeto-mercancía, producto de dicho trabajo. Ahora bien, esta riqueza abstracta tiene un sustrato material constituido por su utilidad, o su valor de uso, el cual requiere para su creación de la acción de un determinado trabajo concreto -el pescador, por ejemplo- sobre una determinada cosa proporcionada por la naturaleza.

Cuando se habla de la riqueza como valor, ésta se representa en una sociedad mercantil, y su fuente, su fundamento, es el trabajo social abstracto, indiferenciado. Cuando se habla de la riqueza como algo útil, capaz de satisfacer necesidades directa o indirectamente, su fuente puede ser sólo la naturaleza, o ésta en compañía del trabajo concre10. Ahora bien, es imposible que algo tenga algún valor si no tiene ninguna utilidad, independientemente de que ésta última sea real o imaginaria. En consecuencia, el trabajo concreto crea la utilidad, esto es, el sustrato material del valor, el cual es generado por el trabajo abstracto. El doble carácter del trabajo, concreto y abstracto, genera el doble carácter de la riqueza considerada como valor de uso y como valor.

Así, El Salvador, pese a tener un territorio de menor tamaño que Olancho, uno de los departamentos de Honduras, tiene más riqueza en térmi- nos de valor, aunque Olancho tenga más riqueza en términos materiales o de recursos naturales, tiene mucho menos personas que trabajan, así como objetos producidos por el trabajo humano. Esto significa que la riqueza en las sociedades capitalistas.se origina en el trabajo, el cual, cuanto más calificado sea, más riqueza genera.

Pero lo que se busca es desarrollar los elementos teóricos que permitan abatir la pobreza en los países capitalistas, sin necesidad de eliminar previamente el sistema capitalista, ni propiciar el desarrollo de empresas capitalistas, como ha sido lo usual. Se tratará, pues, de desarrollar una teoría cuyos principales postulados son: primero, la ineludible tendencia del capitalismo a generar pobreza; segundo, la posibilidad real de desarrollar una estrategia antipobreza que opere en el interior del sistema capitalista; tercero, la necesidad de que la estrategia evite los males del capitalismo y por tanto sea no capitalista; cuarto, una estrategia que aproveche las dinámicas mercantiles pero sin anteponer el mercado a los individuos y, finalmente, una estrategia que potencie el desarrollo individual pero que combata el individualismo.

\section{Las falsas salidas a la pobreza}

Antes de proceder con la propuesta, se revisarán de manera rápida, aunque no por ello en forma menos crítica, algunos planteamientos en torno a las correcciones de los males del capitalismo y particularmente los relacionados con la problemática de la pobreza.

\subsection{Los desvaríos acerca de las bondades de la competencia}

Es común encontrar, inclusive en nuestros miserables países tercermundistas, a quienes creen que los males del capitalismo pueden superarse mediante la promoción de la libre competencia. Por tal razón, cuando los precios de cualquier producto son excesivamente elevados o la calidad de un servicio o una mercancía deja mucho que desear, se recomienda: "competencia". Hasta se dice con aires de mucho saber: "Esto no ocurriría si hubiera competencia". Pero lo más grave es la in- 
genuidad de creer que las leyes económicas pueden contrarrestarse mediante simples leyes jurídicas y/o el fortalecimiento del marco institucional que regula el funcionamiento en el mercado. Es así, por ejemplo, que a los diputados de derecha e izquierda les entusiasma la posibilidad de acabar con los monopolios y oligopolios, mediante la simple emisión de una ley de la libre competencia.

Desafortunadamente para sus sueños de gloria, ocurre que el capitalismo tiende a la concentración y centralización del capital. Esto constituye una ley económica con tanta fuerza social, como fuerza natural tiene la ley de la gravedad, que podrán emitirse todas las normas jurídicas que se quieran, pero en el país y el mundo capitalista seguirán formándose oligopolios y monopolios, y los existentes se acrecentarán y traerán consigo toda la secuela de males y problemas, entre ellos, los generantes de pobreza estructural.

Para comprender mejor lo anterior es preciso hacer algunas referencias sobre la realidad empresarial capitalista de los países con escaso desarrollo industrial. Por ejemplo, se pueden considerar cuáles son las relaciones y acciones de compra-venta que posee una empresa capitalista cualquiera, Las de compra son de maquinaria y equipo, materias primas y auxiliares, recursos financieros y fuerza de trabajo. Los precios de compra los recibe la empresa del mercado y con base en ellos, más una determinada ganancia, establece sus precios de venta. Al vender se relaciona con otras empresas capitalistas o directamente con los consumidores, quienes asumen los precios como dados. En el momento de la compra puede decirse que la empresa está subordinada a los precios y que en la venta subordina vía precios. Más, si por alguna razón, se le conminara a bajar sus precios de venta, la empresa revisaría sus costos y encontraría que los mismos están determinados por los precios de compra, respecto a los cuales no puede hacer nada, aunque sí puede reducir la cantidad de elementos utilizados por unidad producida, esto es, incrementar la productividad del trabajo. Pero si el incremento en la productividad no se acompaña de un incremento en la demanda, habrá una disminución en el número de obreros empleados, es decir, que algunos trabajadores quedarán cesantes. La cesantía puede ser temporal o permanente; si es permanente y generalizada se tendría una causal indiscutible de pobreza. Una ley del capitalismo es: "quien no trabaja es pobre o delincuente, a menos que sea capitalista".

Ahora bien, si la empresa no quiere o no puede incrementar la productividad, la única opción que tendría para disminuir sus precios, vía disminución de costos, sería mediante la reducción de sus costos salariales, ya sea que disminuya salarios o trabajadores. Ambas posibilidades, dependiendo de las magnitudes salariales y de las posibilidades de reubicación de los trabajadores, pueden ser causas generantes de pobreza.

La resultante ha sido beneficiosa para los compradores porque los precios han disminuido, aunque a nivel global ahora existe un número menor de compradores o de poder de compra. Pero si las condiciones fueran otras, cualquier incremento en la produclividad del trabajo o de disminución de los costos salariales, generaría los mismos problemas a los trabajadores y no se traduciría siquiera en una disminución de precios, pero sí en un incremento en los beneficios de los empresarios capitalistas, lo cual les potencia su capacidad concentradora y centralizadora de capital.

Por tanto, la disminución salarial está impedida por nuestra legislación laboral; sin embargo, para nadie es un secreto que los procesos inflacionarios posibilitan a los empresarios realizar grandes disminuciones salariales, las cuales no sólo son toleradas por los gobiernos sino propiciadas por los mismos mediante la congelación de los salarios mínimos. Cuando existe un proceso inflacionario todos los precios se ajustan, aunque ello alimente la inflación, excepción hecha de los salarios, ya que en tal caso se arguye que ello sería inflacionario. De allí que, con competencia o sin ella, los males del capitalismo no pueden resolverse con simples fórmulas procuradoras de la libre competencia entre las empresas. Cuando la competencia es temporal en algunas ramas, causa numerosas quiebras de pequeñas y medianas empresas, lo 
cual se traduce en grandes pérdidas individuales y sociales que, ciertamente, lejos de ayudar a disminuir la pobreza la incrementan.

Con todo, la gran resultante de los procesos capitalistas es la tendencia a que existan cada vez menos èmpresas, pero más gigantescas en cuanto a sus activos y beneficios, mientras que en la otra orilla existen más personas con mayores niveles de pobreza. Esta es la terrible ley de la acumulación de capital, la cual se hace presente de manera inexorable más temprano que tarde en el interior de los países, así como en el mundo capitalista.

\subsection{La falsa dicotomía de producto- res y consumidores}

Anteriormente se hizo referencia a la falsa polaridad entre productores y consumidores y a las consecuencias de ello. Cuando ocurren disminuciones de precios, lo que se gana como comprador-consumidor se pierde como productor-asalariado. Pero lo interesante del fenómeno es que al plantearse de esta manera los problemas en el capitalismo, se encubre totalmente a los verdaderos responsables de la problemática, como son los empresarios capitalistas quienes no aparecen por ningún lado.

Este tipo de enfoques pretende abolir las visiones clasistas, muy del gusto aunque no exclusivos de las disciplinas revolucionarias, las cuales ahora se presentan alicaídas a causa de que algunos seguidores poco ilustrados han preferido optar por la vía fácil de la claudicación y la conversión antes que repensar, replantear y reformular las ideas de los clásicos, atendiendo a las particularidades de la realidad presente.

Así, los comités no gubernamentales, las instituciones oficiales y las leyes de defensa del consumidor son los mecanismos e instrumentos mediante los cuales se busca corregir las imperfecciones y los males del sistema. Sin embargo, es obvio que tales mecanismos han surgido en los países capitalistas de mayor desarrollo donde la pobreza se había reducido a niveles "tolerables", lo cual presupone la existencia de grandes contingentes de consumidores que necesitan ser cuidados en su desenfrenado consumismo. No obstante, trasladar mecánicamente tales prácticas sin antes haber logrado por lo menos reducir los niveles de pobreza absoluta, resulta no sólo de mal gusto sino de una inmensa crueldad. Imagínese usted, dedicar gran cantidad de recursos para velar por los derechos de los consumidores consumistas, los cuales difícilmente sobrepasan el 10 por ciento de la población, mientras que para la inmensa mayoría de salvadoreños su gran problema es cómo satisfacer sus necesidades elementales y básicas de consumo. Pero tanto la izquierda como la derecha tienen sus instituciones de defensa de los consumidores; ojalá que algún día se preocupen por aquellos que no tienen qué consumir, por la situación de pobreza en que se encuentra la gran mayoría de la población y se conozcan sus propuestas para enfrentarla. Pero no con mucho show y poco contenido, sino con realismo, conocimiento y verdadera voluntad para resolver el problema.

\subsection{Apoyos a la microempresa y los informales urbanos o la homeopatía social capitalista}

Diversos países del tercero y también del segundo mundo han tenido una infinita cantidad de experiencias que han pretendido resolver los males del capitalismo mediante prácticas homeopáticas, esto es, recetando más y más capitalismo. Entre estos casos se pueden citar, a manera de ejemplo, los programas de apoyo a la microempresa y a los informales urbanos. Estos son, valga la aclaración, 
aquellos pobres generados por el capitalismo que no se resignan a morir y que mediante iniciativas personales y aisladas buscan captar algún ingreso mediante la producción o la venta de mercancías.

Pues bien, hacia estos pobres, que no son tan pobres como otros del área rural, van dirigidos muchos consabidos programas de asistencia técnica, crediticia y de comercialización, con los cuales se espera hacer crecer a estas empresas, crecimiento que se traducirá en mayor generación de empleo, nuevos mecanismos de obtención de ingresos y como obvia resultante: se atacará la pobreza hasta abatirla. Sin embargo, la resultante es que se incrementa el número de ocupados en el sector no capitalista de la economía y la magnitud de los pobres. Algo ocurre en el sistema que impide que en todo este ámbito de la actividad económica no se obtengan los resultados esperados. Es más, hasta ocurre lo inesperado, como el que los niveles de la pobreza se incrementen.

La explicación de lo anterior se encuentra en la relación de subsunción indirecta existente entre las formas de trabajo no capitalistas y el capital, por lo que aquellas se convierten en instrumentos indirecios de valorización de éste'. Este fenómeno de la subsunción indirecta es de suma trascendencia para comprender no sólo el problema anterior, sino la dinámica de la presencia, la ausencia, el desarrollo, la modificación y el resurgimiento de estas formas económicas no capitalistas. Es interesante percatarse que, incluso, cuando en los países primermundistas se hace presente la crisis, surgen o resurgen estas actividades no capitalistas y son toleradas por el capital, no sólo porque posibilitan la reproducción de la fuerza de trabajo sin ningún costo para el mismo, sino porque también le significan vías indirectas de valorización o, si se prefiere, fuentes alternas de beneficios.

Los apoyos brindados para el desarrollo de los campesinos son semejantes: asistencia técnica, crediticia y de almacenamiento y/o de comercialización. Sin embargo, los campesinos siguen sumidos en su pobreza. Pero, ¿qué es lo que falla? Además del problema esencial ya mencionado - la subsunción indirecta-, los promotores o agentes de extensión, para el caso del agro, exigen de los "beneficia- rios" conductas que no corresponden a sus lógicas de funcionamiento. No se les puede exigir a estos sujetos que actúen con la racionalidad del máximo beneficio, propia de la lógica capitalista, cuando con su actividad buscan obtener su medio de vida, ya que su racionalidad es garantizar su reproducción material y espiritual. Lo que les preocupa e importa es satisfacer sus necesidades personales y las de su familia, -la cual generalmente no es nuclear sino ampliada-; garantizar la supervivencia de la totalidad del grupo familiar, de allí que su actividad si bien es económica, no es crematística.

\subsection{Programas de los gobiernos para combatir la pobreza}

Ciertamente, con los gobiernos ocurre que o nunca han tenido programas para combatir la pobreza, o cuando dicen poseerlos carecen de todo contenido lógicoeconómico, ya que cómo esperar que los pobres no sean pobres mediante ayudas alimenticias a los escolares o mediante las llamadas "escuelas saludables", o los subsidios a la vivienda, o brindando consultas médicas gratuitas, o al introducir el servicio de agua y alcantarillado a las comunidades; no es posible combatir la pobreza si no se tratan las causas de la misma. Lo que lós gobiernos implementan es necesario pero no como medidas para combatir la pobreza, porque no la atacan como nos lo revela la realidad. Los servicios gratuitos que brindan los gobiernos revelan la existencia de pobres y cuando los mismos se incrementan, seguramente es porque la pobreza se ha incrementado. Esto es asi porque quien no es pobre no acude a los servicios gratuitos del gobierno. En consecuencia, si un gobierno presta más servicios gratuilos, es porque lejos de combatir la pobreza, la propicia. Esta situación se presentó en muchos países luego de implementar los llamados programas de ajuste estructural.

Ante lo sostenido previamente resulta interesante citar el planteamiento siguiente:

"Al inicio del nuevo año y a las puertas del siglo veintiuno, con una visión amplia y clara del futuro, nuestro país necesita nuevas ideas, nuevos líderes y nuevas alianzas para impulsar de manera sostenida el desarrollo integral que permita erradi-

1. Para un desarrollo completo de esta visión, consúltese Aquiles Montoya, Informalidad urbana y nueva economía popular, UCA Editores, cap. 3, 1995. 
car las causas generadoras de la pobreza y de la marginación social"2.

Amén de cierta incoherencia lógica en el planteamiento, que no es motivo de discusión en este artículo, hay que destacar lo positivo del mensaje del señor presidente de la república cuando sostiene que, "nuestro país necesita nuevas ideas, nuevos líderes y nuevas alianzas... para erradicar las causas generadoras de la pobreza y la marginación social". Se está total y absolutamente de acuerdo con estas frases, ya que como se ha intentado mostrar, ciertamente, se necesitan nuevas ideas. ¿Nuevos líderes? Resulta tan obvia su necesidad que ni falta hace argumentar al respecto. $Y$ en cuanto a la necesidad de una nueva alianza, pues, sí. Hasta él lo dice.

Con todo, lo más importante son las nuevas ideas y por ello es conveniente efectuar algunas reflexiones al respecto. Como se ha señalado en otra ocasión, las ideas racionales llevan en sí mismas la exigibilidad de ser asumidas por otros de mente racional, de allí que lograr comunicar una buena idea es lo máximo que le puede ocurrir a un académico.

Pues bien, hasta ahora se han presentädo algunas críticas a las falsas salidas a la pobreza, ahora se procederá a mostrar una propuesta, que no posee ninguna inspiración divina y tampoco ha brotado de una fe ciega en los pobres, ni mucho menos se trata de una mera especulación propositiva. Esta propuesta es el resultado de varios años de investigación teórica y empírica. La primera ha permitido determinar los límites de lo posible y, la segunda, la realidad de los sueños utópicos.

2. Razones para combatir la pobreza y cómo lograrlo en el capitalismo

\subsection{Las razones}

Ciertamente, las razones para combatir la pobreza son una obviedad; sin embargo, éstas varían según sean los intereses, la formación, las creencias o la disposición de las personas. Incluso, hasta puede ser animante hacer referencia a algunas, ya que pudiera ser que no se tuviera conciencia de la necesidad de acabar con la pobreza. Abatir la pobreza en una sociedad capitalista significa dotar de medios de compra a los pobres para que puedan satisfacer sus necesidades materiales y espirituales, con lo cual se genera una nueva demanda de consumo y, de manera inducida, nuevas inversiones para satisfacer el cúmulo de la nueva demanda. En consecuencia, abatir la pobreza debía ser de interés para los empresarios capitalistas, quienes verían mejorar sus negocios y beneficios. Por tal razón, este sector de la sociedad está a favor de abatir la pobreza, aunque puede disentir en la manera de hacerlo, por ejemplo, los empresarios nunca han estado dispuestos a asumir algunos sacrificios económicos temporales, cuando se ha propuesto la necesidad de redistribución de la riqueza como medida de ataque frontal a la pobreza.

Otros, en cambio, quizá no tengan un interés económico tan directo e inmediato como los empresarios capitalistas; sin embargo, el poder garantizarse el disfrute tranquilo y seguro de sus bienes los llevaría al convencimiento de que sería mejor que no hubiera pobres $y$ que, obviamente, es responsabilidad del gobierno enfrentar tal problema y que ellos, rentistas de dorada alcurnia, suficiente tienen ya con los impuestos a la renta como para venir con los nuevos impuestos al patrimonio, "disque" para dotar a las municipalidades de recursos de manera que promuevan el desarrollo local. De igual manera, este sector tradicional está a favor de combatir la pobreza, pero nunca con medidas que afecten sus intereses, como una reforma agraria, por ejemplo, que hasta podría ser aceptada y promovida por la burguesía industrial.

Existen también aquellos que sin poseer ningún interés económico, ni siquiera material, poseen motivos de orden religioso que les impulsa a luchar sin miedo y sin cuartel por la causa de los pobres. Concebida la pobreza como un pecado estructural se combate como cualquier otro pecado. En esta lucha contra el pecado, como es obvio esperar, se entra en conflicto con los pecadores, con

2. Mensaje de año nuevo del presidente de la república, señor Armando Calderón Sol, El Diario de Hoy, 5 de enero de 1998. 
los supuestos causantes de la pobreza, aunque unos y otros digan estar a favor de abatir la pobreza.

También es común encontrar aquellos para quienes los pobres no deben existir por la sencilla razón de que también son seres humanos $\mathrm{y}$, por ende, no existe razón para que la sociedad los margine y excluya de los beneficios a que tienen derecho como cualquier otro ser social. A estos enemigos de la pobreza es común que se les mezcle - a su contenido profundamente humanistao atribuyan mezquinos intereses políticos partidistas, y aunque no existan razones valederas para disentir de la necesidad de combatir la pobreza, se termina por perseguir a quienes sin padecer la pobreza, quizá tienen las razones más genuinas para combatirla. Estos son aquellos a quienes después basta con adjudicarles cualquier epíteto del tipo terminado en "ista", como comunista, anarquista, socialista, agrarista, etc., para que pronto aparezcan en la lista de los que habrá que desaparecer. Y todo por combatir la pobreza, combate con el que nadie parece estar en desacuerdo.

También existen quienes están a favor de abatir la pobreza por la sencilla razón de que los pobres "les caen mal", les desagradan por su "incultura" y/o su mal gusto, por su haraganería e ignorancia, por que son viciosos y perversos, e inclusive, hasta feos. Obviamente, les parece que la vida sería mejor sin pobres que les ensucien el carro, que les pidan un peso, que les puteen o les roben al menor descuido y por cualquier razón.

Finalmente, los gobiernos también dicen estar a favor de combatir la pobreza, desafortunadamente nunca han logrado entender ni las causas reales, ni la forma efectiva de hacerlo. De allí que en esta propuesta, los gobiernos siempre deberán combatir la pobreza pero no tanto por las razones del pasado, sino porque en términos de costo-beneficio sociales resulta mejor para todos que no existan pobres, pero vistas así las cosas, será necesario también que el gobierno modifique la forma de combatir la pobreza, lo cual se analizará oportunamente.

\section{2. ¿Cómo abatir la pobreza en el capitalismo?}

Como se podrá comprobar en el desarrollo de este planteamiento, se han dejado por fuera todas las propuestas del pasado relacionadas con el cambio de sistema como condición primera para erradicar la pobreza. La hipótesis de que la solución para erradicar la pobreza es cambiar el sistema sencillamente no se considera. De igual manera se descarta la salida homeopática de proponer más y más capitalismo, ya suficientemente probada sin éxito en el tercer mundo. También se excluyen las reformas radicales y profundas que atentan contra la propiedad privada. De igual manera se excluye la participación directa del gobierno por ineficiente y paternalista, al menos en la forma que ha actuado hasta hoy.

Esta propuesta, sin buscar a propósito conciliar las distintas razones para combatir la pobreza, tal parece que lo consigue ya que no se toca el sistema, no se busca afectar a los empresarios, se respeta la propiedad privada, no hay reformas radicales y ni siquiera se concibe como condición previa para erradicarla la toma del gobierno. Bastará que éste actúe paralelamente con otros agentes, de forma racional y eficiente, y respete el carácter de sujetos de los pobres. Ciertamente la tarea es bastante difícil, pero si se logrará desarrollar la teoría conforme a lo ofrecido, no deberían existir resistencias para implementarla, lo cual resulta ser más que estimulante para formularla.

\subsubsection{Algunos presupuestos}

Abatir la pobreza en el capitalismo exige de la consideración de muchos presupuestos que permitan tener una comprensión esencial de la pobreza en sí misma y de sus causas generantes. Se retomarán aquellos que a nuestro juicio son insoslayables. Primero, que el capitalismo genera de suyo pobreza; segundo, que pese a ello es posible desarrollar una estrategia antipobreza que opere en el interior del sistema capitalista; tercero, una estrategia que evite los males del capitalismo y que, en consecuencia, sea no capitalista; cuarto, una estrategia que aproveche las dinámicas mercantilistas pero sin anteponer el mercado a los individuos; quinto, una estrategia que potencie el desarrollo del individuo pero que combata el individualismo. A estos postulados previamente presentados se añaden unos cuantos más. Sexto, de manera general, los pobres no son pobres por haraganes o falta de educación; séptimo, de manera general los pobres son pobres por falta de trabajo $y$, consecuentemente, por falta de ingresos; octavo, de manera particular puede haber pobres a causa de enfermedad, invalidez, o inclusive por haraganería.

Pues bien, hay que reflexionar un tanto sobre los presupuestos a fin de hacer compresiva su necesidad. Es importante tener presente que el capi- 
talismo genera pobreza a fin de no caer en la homeopatía social, a la que ya se ha hecho referencia, y proponer más capitalismo para combatir los viejos males del sistema. Pero también es necesario establecer que pese a ello es posible combatir la pobreza en el capitalismo, a fin de no caer en aquellas propuestas del pasado, las cuales sostenían que era necesario primero cambiar el sistema para luego acabar con la pobreza. Cuando se sostiene que el abatimiento de la pobreza se propone "en el sistema", se quiere decir que se hará en una formación social capitalista, ya que el modo de producción capitalista seguirá siendo el dominante; sin embargo, las actividades económicas que desarrollarán quienes buscan superar su pobreza tienen que ser no capitalistas, de tal manera que se eviten o minimicen algunos males propios del capitalismo.

Al rechazar la forma capitalista de la economía, en la propuesta, no se rechaza la forma mercantil, por el contrario, se reconoce y acepta el funcionamiento del mercado en las relaciones con el exterior del sector, ya se trate de empresas capita-

listas, consumidores asalariados o bien, del gobierno, incluso, mucha de la distribución en el interior del nuevo sector se hará vía mercado. Mientras no se llegue al reino de la abundancia y las personas sigan concibiendo como valores los productos de su trabajo y no como meros satisfactores de sus necesidades, es preciso acudir al mercado para asegurar una distribución más o menos eficiente de lo producido, aunque no se confíe en el mismo para la asignación de los recursos productivos en el interior del nuevo sector, por supuesto.

También es de interés potenciar y estimular el desarrollo del individuo, a diferencia del deterioro en la autoestima generado por el capitalismo a causa de estimular un individualismo exagerado y enfermizo, bueno tan sólo para generar frustración y desengaño entre los jóvenes ante su incapacidad de saciar su consumismo. Interesa que las personas se aprecien por lo que valen y no por lo que tienen. Enfocar de esta manera las valoraciones de las personas conduce a considerar en su justo valor a las grandes mayorías, a diferencia del capitalismo donde ocurre lo contrario. Importa elevar el amor propio de las mayorías populares, no sólo porque tienen razones sobradas para no despreciarse, sino porque al hacerlo potencian sus grandes dotes creativas, necesarias e importantes en el camino a la solución de sus muchas carencias materiales.

Se suele justificar la pobreza al aducir que los pobres lo son por haraganes e incultos pero, ¿cómo es posible que sean haraganes si cuando se les contrata y paga un salario generan la riqueza que otros disfrutan? Es obvio que los empresarios por más que desprecien a los trabajadores, no podrían hacer producir a sus negocios si no existieran trabajadores que les vendan su fuerza de trabajo. Por otra parte, no es raro encontrar entre los pobres a personas con igual educación que los no pobres; además, a los ricos no les viene la riqueza de su educación, pero si pueden educarse es gracias a su riqueza.

Que los pobres lo son por falta de trabajo es tan obvio como que en los períodos de crecimiento económico excepcional se reduce la magnitud de los mismos. Aunque más temprano que tarde, el número de trabajadores nuevamente es excesivo en relación con las necesidades de explotación del capital. Así, la magnitud de los pobres se incrementa en proporción a los que carecen de empleo y $/ 0$ a la reducción de los salarios de quienes aún permanecen ocupados. Esta es una de esas realidades terribles que los apologistas del capitalismo no desearían que fuera así y, quizá por ello, son muy dados a negarla $u$ olvidarla hasta que estalla una nueva crisis social. Dar una explicación detallada del por qué se "autoderrota" la prosperidad no es posible por el limitado espacio de este artículo. Valga nada más señalar que su explicación se encuentra en la tendencia del capitalismo a la concentración de la riqueza, de lal manera que al transcurrir el tiempo la demanda se rezaga de la oferta, aunque se acuda a los mecanismos de crédito para aproximar la demanda a la oferta; ello funciona de manera temporal, ya que es obvio que no se puede vivir indefinidamente del crédito.

$Y$, finalmente, se desea dejar constancia que si bien es cierto que existen casos aislados en los cuales la haraganería, la carencia de educación, la 
enfermedad y otras razones semejantes mantienen a las familias en la pobreza más abyecta, no es posible generalizar las causas de la pobreza a partir de tales casos particulares, en tanto que existen otras familias que también son pobres y no poseen ninguna de esas características. Pero, sobre todo, porque se ha observado históricamente que en el capitalismo la magnitud de la pobreza disminuye cuando se incrementa la magnitud del empleo y de los ingresos.

\subsubsection{Cómo abatir la pobreza}

Luego de las formulaciones anteriores, la fórmula misteriosa que posibilitaría abatir la pobreza resulta más que sencilla y quizá hasta excesivamente obvia: generar empleo que se traduzca en ingresos o medios de vida para garantizar la reproducción material y espiritual de la familia trabajadora, esto es, superar la línea de la pobreza.

Ahora bien, tales empleos tendrían el carácter de no asalariados, ya que no se está proponiendo ninguna fórmula trivial, al estilo del crecimiento económico, tan usadas en el pasado y aún ahora bajo la modalidad de teoría del rebalse. Tampoco se está sugiriendo la generación individual de autoempleo, propia de los informales urbanos o del campesinado, ya que se trata de experiencias no exitosas.

Nuestra propuesta de generación de empleo parte de aquellas experiencias de Desarrollo Económico Comunitario (DEC), existentes principalmente en el área rural de nuestro país. Se trata de las organizaciones comunitarias de repobladores, repatriados y desmovilizados surgidas durante y con posterioridad al conflicto políticomilitar, gracias al apoyo de distinta naturaleza brindado tanto por organismos no gubernamentales nacionales como internacionales ${ }^{3}$.

Esta propuesta parte de esa realidad, que se ha denominado DEC (Desarrollo Económico Comunitario), pero no se limitará a repetirla o a brindar un cuadro sistematizado de la misma. No se procederá de esa manera por una razón muy sencilla y es que las comunidades no han logrado alcanzar el pleno empleo, de allí la necesidad imperiosa de reflexionar en torno a cómo superar esa problemática. De lograrlo de buena manera, no sólo se estaría colaborando con las comunidades sino que se resolvería el problema planteado: abatir la pobreza en el capitalismo.

La resolución del desempleo es una meta o un horizonte, pero para llegar a ese punto es preciso previamente revisar el cúmulo de factores positivos con que cuentan a su favor las comunidades, sin los cuales, sencillamente, sería un abuso, una ilusión o un puro desvarío cualquier propuesta de nuestra parte.

\subsubsection{Factores que posibilitan abatir la pobreza}

Estos factores que hacen posible abatir la pobreza son realmente una serie de características propias de las comunidades previamente referidas $y$, por tanto, se trata de una realidad fáctica. Lo primero y fundamental que se observa en estas comunidades es que están organizadas. La organización tiene un fin expreso: realizar sus actividades económicas que para ellas es primordial. No es una organización con fines políticos, ni siquiera sociales o culturales, como había sido lo tradicional, se trata de una organización con fines económicos. Esto no significa que lo político, lo social o cultural esté ausente. No, claro que no. La organización con tales fines sigue existiendo. Pero además existe la organización con fines económicos. Y esto, precisamente, viene a marcar un giro rotundo $y$ radical en todo el accionar comunitario. Se pasa de la protesta a la propuesta. De la exigencia y de la demanda tradicionales se avanza hacia propuestas y demandas de otra naturaleza. De manera ilustrativa se puede señalar que en lugar de demandar créditos subsidiados, buscan la manera de generar o crear sus propios mecanismos o instrumentos crediticios. La organización económica es su base y fundamento.

3. El Desarrollo Económico Comunitario, diagnóstico socioeconómico de 100 comunidades, Aquiles Montoya, inédito. 
Sus propios mecanismos, sus propios instrumentos... Se desea destacar, en segundo lugar, otra característica que se presenta en las comunidades: poseer iniciativas propias, sin esperar a que les lleguen a decir qué y cómo actuar de fuera. Esto es de suma importancia porque les define de entrada como auténticos sujetos de sus proyectos y actividades. Ciertamente necesitan ayuda y la piden cuando la requieren y en la forma que les resulta más conveniente. Se trata, pues, de sujetos con iniciativas propias.

En tercer lugar, existe otra que se desprende de la anterior y tiene relación con la forma en que las comunidades trabajan y con sus nexos con agentes externos a la comunidad. Nadie extraño o ajeno a ellas impone ni dispone cómo deben ser las cosas, son ellos, de manera organizada, quienes deciden qué es lo más conveniente para la comunidad. Razón por la cual el trabajo de los organismos no gubernamentales se reduce a un simple apoyo, a un acompañamiento, pero eso sí, muy dispuesto a colaborar en el momento preciso en que se requiera para la buena marcha de la comunidad. De esta manera, el apoyo externo no reemplaza a los sujetos, ni lós hace dependientes, por tal motivo estos organismos no gubernamentales pueden y deberán alejarse más tarde o más temprano de las comunidades. Existe capacidad de decisión propia.

En cuarto lugar, hay que señalar que es propio de las comunidades la solidaridad entre sus miembros, lo cual induce a la cooperación, la ayuda mutua y enfrentar de manera conjunta sus múltiples problemas. Esta característica unida a las anteriores es lo que posibilita la existencia de formas colectivas; cuando esta modalidad de la propiedad, del trabajo, elc. se presenta como la más conveniente para las necesidades y los intereses del grupo. En otras palabras, no definen a priori las formas de propiedad, del trabajo, de la venta de lo producido, de la solicitud de créditos, etc. Según sea el caso y las circunstancias, así optan por una forma u otra. Precisamente porque están convencidos que se trata de meras formas y que lo determinante es el contenido. El ser solidarios les marca su accionar, ya sea colectivo o individual.

Una quinta característica está relacionada con las posibilidades reales que existen en las comunidades de poner en práctica la equidad de género, en razón de que la misma realidad bélica que les tocó vivir condujo a que las mujeres jugaran un papel preponderante en las distintas actividades económicas, sociales, políticas, etc., al punto que existen comunidades en las cuales las personas adultas en su mayoría son mujeres y son ellas quienes controlan los puestos de dirección en las distintas organizaciones de la comunidad. Tales experiencias muestran, sin discusión, las capacidades reales de las mujeres y la sinrazón de su ubicación desigual en la sociedad machista.

En sexto lugar, se observa en las comunidades que han resuelto sus necesidades sociales de educación, salud, agua potable, energía eléctrica, comunicaciones, etc. de manera organizada, con o sin el apoyo del gobierno. Cuando el gobierno no ha podido o no ha querido colaborar, han sido las comunidades las que han creado sus propios sistemas de educación y salud, sus propios servicios de agua potable, $\mathfrak{c}$ inclusive, de energía eléctrica. Todo ello gracias a la cooperación externa y al manejo eficiente de los recursos obtenidos. Con sus esfuerzos e inicialivas van creando un desartollo social comunitario.

En séptimo lugar cabe destacar la receptividad de las comunidades a las prácticas ecológicas, lo

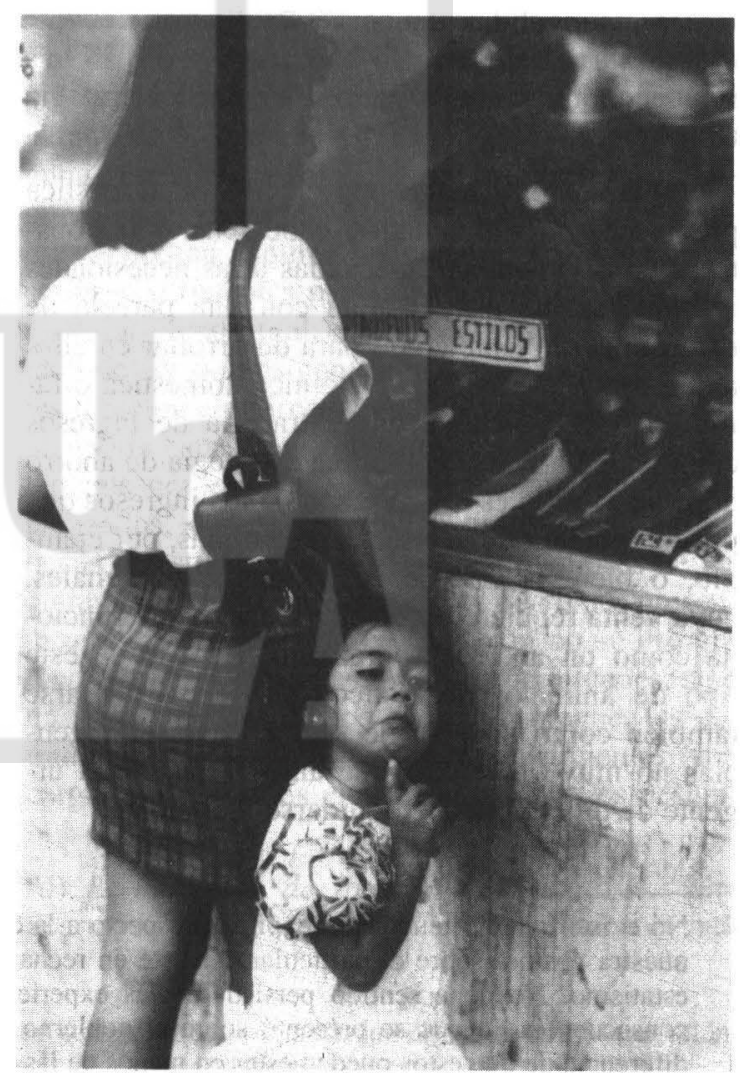


cual seguramente está determinado por un hecho fundamental: el acceso a la propiedad de la tierra en la mayoría de comunidades.

Cabría señalar, en octavo lugar, que la propiedad de la tierra, así como la de otros activos existentes en las comunidades, no asume la forma de propiedad privada capitalista. Puede revestir una forma colectiva: de grupos, de asociaciones y sociedades cooperativas, de la asociación comunitaria, de la familia, etc., pero sin llegar nunca a la forma capitalista típica. Lo que se busca, como ya se señaló, es la forma más funcional a sus actividades, así como también que les brinde seguridad a sí mismos y sus descendientes.

En noveno lugar, se observa también que las comunidades organizadas no desprecian el poder local, de allí que han buscado controlar el mayor número de alcaldías posibles a fin de emplear el poder municipal para potenciar, consolidar e incrementar el desarrollo socioeconómico comunitario, base de su estrategia antipobreza.

Finalmente, y como una décima característica propia de las comunidades, cabe señalar la construcción de viviendas adecuadas a las necesidades campesinas, ya que cuentan con una parcela de extensión suficiente como para desarrollar en ellas algún tipo de actividad económica doméstica o familiar, que constituye una estrategia de ingresos complementaria, así como una estrategia de ahorro doméstico. Ello es así en razón de los ingresos que pueden obtener de la crianza de gallinas, por ejemplo, o bien, la cría de cerdos u otros animales, cuya venta requiere un mediano plazo, que funciona como un ahorro programado. La cría de este tipo de animales domésticos puede considerarse también como un plan de seguros ante emergencias no muy graves, ya que ante la necesidad urgente de dinero pueden liquidarse fácilmente.
Como se puede observar, las comunidades que sirven de referente para esta propuesta antipobreza no constituyen comunidades cualesquieras, tomadas indistintamente y al azar. Son comunidades que poseen una serie de características especiales que sería preciso alcanzar previamente en cualquier núcleo poblacional marcado por la pobreza y al cual se buscará ayudar, ya sea como organismo no gubernamental, o bien como gobierno.

\subsubsection{Nueva función de los gobiernos en la lucha contra la pobreza}

Independientemente de cuales sean las razones, políticas, sociales, jurídicas o económicas, lo cierto es que los gobiemos están obligados a enfrentar la pobreza. Y así lo ven y así lo entienden; por ello han realizado numerosos esfuerzos, desafortunadamente todos, sin excepción alguna, han sido en vano y la pobreza sigue campante en los distintos países capitalistas. Ha ocurrido, inclusive, que en algunos momentos históricos, ciertos gobiernos sin tener conciencia de las causas generantes de la pobreza y la forma de combatirla, intuitivamente han decidido combatirla mediante la generación de empleos y de manera temporal han obtenido resultados exitosos. Desgraciadamente para los gobiernos y los pobres, los empleos generados por cualquier acción gubernamental no son sostenibles en el tiempo, y no pueden mantenerse más que de manera coyuntural. Es más, los ejércitos de burócratas y militares que existen en los gobiernos de hoy, constituyen un pesado lastre sobre las finanzas públicas y más temprano que tarde se comenzará a cuestionar su existencia aunque cumplan, de manera ineficiente e indebida, una función antipobreza.

Esta propuesta exige que la fúnción de los gobiernos centrales ${ }^{4}$ parta del convencimiento de que en términos de beneficio-costo sociales resulta más eficiente y conveniente contribuir a la exis-

4. No existe una diferenciación explícita respecto a la contribución de los gobiernos municipales, en razón de que nuestra postura sobre el particular consiste en rechazar la visión del desarrollo local en lo que tiene de microestatismo. No tiene sentido persistir en las experiencias estatales fallidas, sólo que ahora a nivel micro. En consecuencia, lo que se presentó sobre el gobierno central es trasladable a los gobiernos municipales, con la diferencia de que estos pueden estar en manos de las comunidades organizadas. 
tencia de puestos de trabajo en "el nuevo sector social"s, que atender a sus necesidades sociales de manera gratuita, así como a las necesidades de seguridad de los otros sectores sociales. El punto por determinar, entonces, sería cómo realizarán su contribución los gobiernos. Para ello, la contribución gubernamental constaría de distintos momentos: (a) el momento de la organización, (b) el de la dotación de activos, (c) el de la capacitación, (d) el de los servicios sociales y (e) el de la conservación del funcionamiento.

(a) El momento de la organización. Este momento es sumamente delicado ya que

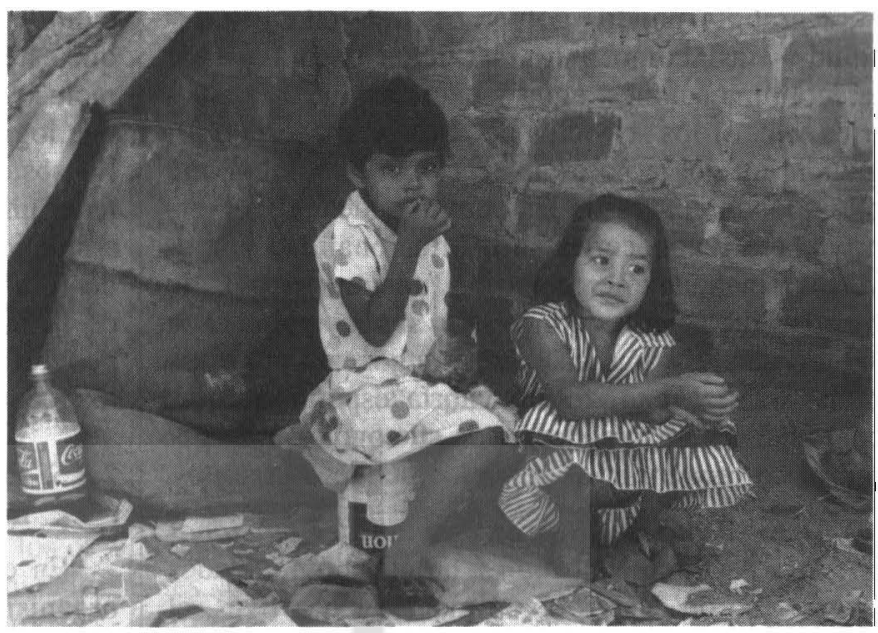
en él se definirá el futuro de la comunidad y los gobiernos. Si bien deben propiciar la organización de comunidades pobres, en ningún caso deberán proceder a su organización. A lo sumo, su incidencia deberá consistir en señalar que si estuvieran organizados podrían contar con algún tipo de ayuda de parte del gobierno central o municipal como una forma de presionar hacia la organización. Pero ésta deberá siempre ser conseguida por y para las comunidades de pobres.

(b) El momento de la dotación de activos. Si bien el gobierno no es ni puede ser la única fuente en la caplación de activos, sí debe ocupar un lugar preponderante en tal actividad. Hay que recordar que entre las funciones del gobierno se encuentra la función redistributiva, mediante la cual el gobierno capta ingresos vía impuestos de unos sectores de la sociedad y los transfiere hacia aquellos más necesitados. En consecuencia, una forma más eficiente de llevar a cabo tal función, sin necesidad de eaer en los subsidios, es facilitarle a los pobres la ādquisición de activos, de tal manera que ellos puedan realizar sus actividades económicas a fin de poseer empleo e ingresos seguros, así como también dignidad. La pérdida de la autoestima quizá es más nociva para las personas que la carencia de ingresos a causa del desempleo. Por otra parte, los mecanismos para facilitar la adquisición de activos por parte de las comunidades pobres pueden ser: donaciones directas del gobierno o gestiones ante donantes del exterior, créditos de largo plazo, bajos intereses y períodos de gracia,

otorgados directamente o gestionados ante organismos internacionales, transferencia de activos propiedad del estado, etc.

(c) El momento de la capacitación. En este aspecto, como en los otros momentos, los gobiernos nunca deben ver los desembolsos monetarios que realicen como gastos, sino como una inversión social de alta rentabilidad. Al dotar de activos a los pobres, al capacitarlos para su manejo, etc. se está garantizando que csa población ya no tendrá ninguna dependencia del gobierno, ni constituirá ninguna amenaza social. Al contar con empleos e ingresos podrán adquirir los bienes y servicios necesarios y suficientes para asegurar su reproducción material y espiritual, en consecuencia, habrán dejado de ser pobres con todos los beneficios sociales directos e indirectos que ello implica. Los servicios de capacitación pueden ser prestados directamente por el gobierno mediante sus entes especializados, o bien, se pueden gestionar u otorgar becas de estudio para los jóvenes miembros de las comunidades. Por otra parte, hay que tener presente que los servicios de capacitación no se otorgarán de manera permanente a las comunidades, sino que una vez capacitados para el despegue, las comunidades obtendrán los ingresos suficientes para cargar ellos mismos en el futuro con tales desembolsos.

(d) El momento de los servicios sociales. Este apartado se refiere a los servicios prestados de ma-

5. Por nuevo sector social se entiende aquel constituido por una serie de comunidades organizadas, que le están haciendo frente a la pobreza mediante la generación de actividades económicas conjuntas, solidarias, etc. 
nera gratuita por los gobiernos -de educación y salud-, así como a los servicios pagados -de telecomunicaciones, agua y excretas, energía eléctrica, etc. Si los servicios no existieran, sería obligación del gobierno establecerlos. Si contaran con ellos por iniciativa de las comunidades, el gobierno deberá reconocerles su institucionalidad y apoyarlos financieramente en su funcionamiento, de manera que aquellas concentren sus inversiones en actividades económicas que les generen ingresos monetarios. En un futuro cabría esperar que las comunidades una vez superada su condición de pobreza, no requerirán de servicios públicos gratuitos.

(e) El momento de la preservación del funcionamiento. A fin de contribuir a que las comunidades en proceso de desarrollo se mantengan activas, el gobierno debe definir una política de aprovisionamientos. Esta debe establecer que las comunidades con capacidad de suministrar bienes y servicios demandados por el gobierno, serán elegidas preferentemente sobre cualquier otra empresa nacional o extranjera para suministrar los bienes y servicios requeridos. La lógica de este planteamiento es que resulta más económico y conveniente, en términos sociales, contribuir a preservar los empleos en las comunidades que cargar con los gastos directos e indirectos que acarrearía la existencia de esas comunidades en situación de pobreza. De allí pudiera ocurrir, por ejemplo, que un par de zapatos para un agente de la Policía Nacional Civil tuviera un precio mayor al adquirirlo en una comunidad que en una empresa industrial capitalista; sin embargo, la vida económica de una comunidad podría depender del suministro de calzado al gobierno; en cambio para la empresa industrial tan sólo significaría dejar de ganar unos cuantos miles de colones. Por tanto, las compras deberían hacerse a la comunidad, pese al mayor precio, porque a la larga unos cuantos colones de más posibilitarán el ahorro a la sociedad de muchos miles de colones. Además, el apoyo al funcionamiento de las comunidades requiere otro tipo de apoyos por parte de los gobiernos, como por ejemplo, la autorización de manera excepcional de su propio sistema financiero basado en cooperativas de ahorro y crédito y bancos comunales; la autorización de mecanismos expeditos de importación de insumos; el acceso a tecnología de punta; el apoyo en la implementa- ción de programas agroecológicos, etc. La idea es que este sector cuente con un tratamiento especial, incluso se vuelva un sector privilegiado a fin de que logre consolidarse y avanzar hacia su desarrollo sostenido. Esta situación de privilegio podría tener una duración definida previamente para cada comunidad en particular, por ejemplo un mínimo de 10 años y un máximo de 20 años, dependiendo de la naturaleza de sus actividades, su ubicación geográfica, la calidad del suelo y la dotación de los recursos naturales con que cuente.

\subsubsection{Función de los organismos no guberna- mentales en la lucha contra la pobreza}

En cuanto a la función que corresponde a los organismos no gubernamentales vinculados con los sectores populares y que están comprometidos a luchar contra la pobreza, es de suma importancia tener en cuenta los planteamientos siguientes: en primer lugar, que los organismos no gubernamentales descarten de una vez y para siempre la promoción humana asistencialista; en segundo lugar, que realicen una promoción educativa que vaya desde la educación formal hasta la ideológica, pasando por la formación técnica en el más amplio sentido del término; en tercer lugar, que continúen canalizando recursos financieros desde los países ricos hacia los pobres, ello es parte de la solidaridad humana; en cuarto lugar, que no pretendan convertirse en sujetos de la estrategia antipobreza, sino tan sólo en acompañantes, en ayudantes, en facilitadores, esto es, que busquen impulsar una promoción humana participativa $y$, en quinto lugar, que tengan en cuenta que si bien no se pretende transformar el sistema como condición previa para abatir la pobreza, tampoco se trata de promover actividades propias de la forma de funcionamiento capitalista ${ }^{6}$.

Ciertamente, se considera que el aporte de los organismios no gubernamentales es de suma trascendencia, ya que ha sido por medio de su' colaboración y apoyo que muchas comunidades se encuentran en condiciones de vida y trabajo muy superiores a como era su realidad en el pasado. Ahora bien, se ha generalizado el Irabajo de los organismos no gubernamentales, lo cual no significa que no existan otros de distinto tipo, con distintas

6. Algunas ideas se tomaron de Aquiles Montoya, "El desarrollo y la nueva economía popular". revista Realidad Económico-Social, enero-febrero, 1993, p. 72. 
prácticas, distintos fines e intereses, a tal punto que es posible encontrar algunos que niegan la naturaleza y los fines propios de una ONG. Se entiende, pues, que aqui se hace alusión a aquellos organismos no gubernamentales cuya actividad no está determinada por intereses político-partidarios, religiosos o económicos. Al menos, en lo que al combate de la pobreza se refiere, parece que estos organismos deberían estar animados por principios estrictamente humanistas, ya que de esa manera podrán ser constantes en su labor, pese a los muchos contratiempos que es común enfrentar en este tipo de actividad?

En cuanto a la colaboración que presten los organismos no gubernamentales a las comunidades que buscan abandonar su condición de pobreza es posible establecer casi los mismos momentos diferenciados que se señalaban a propósito de la contribución gubernamental: (a) el momento de la organización, (b) el de la dotación de activos, (c) el de la capacitación, (d) el de los servicios sociales, y (e) el del adiós o de la conservación del funcionamiento.

(a) El momento de la organización. Es como el fruto de los primeros contactos de un determinado organismo no gubernamental con cierto núcleo poblacional que se encuentra en condición de pobreza. Este organismo logra estimular a la comunidad para que forme una directiva provisional, la cual se encargará de realizar trabajo de concientización entre los distintos miembros de la comunidad hasta llegar a una primera asamblea general, en donde se eligirá la primera directiva formal. Los promotores del organismo no gubernamental, si bien han animado y acompañado el proceso, no han sido un factor determinante en cuanto a la elección de los directivos por parte de la comunidad. Desde el principio, la ONG debe tener una actitud de respeto en cuanto a las decisiones de la comunidad.

(b) El momento de la dotación de activos. En este proceso, la labor de la ONG se torna vital, ya que gracias a su ayuda la comunidad podrá tener acceso a los activos que requiere para iniciar su despegue económico. Habrá organismos no gubernamentales que directamente puedan suministrar recursos económicos a las comunidades con las cuales trabajan; sin embargo, la mayoría asesora a las comunidades sobre cómo formular proyectos que les permitan tener acceso a los recursos monetarios, generalmente provenientes de donantes del exterior. Importa en este punto que las ONGs no sangren a las comunidades de los recursos que les han ayudado a obtener.

(c) El momento de la capacitación. Si bien la capacitación puede tener una diversidad de áreas, en el trabajo comunitario es posible dividirla en dos grandes áreas: la capacitación relacionada con el área social y aquella vinculada con las actividades económicas. En la actualidad, existen organismos no gubernamentales especializados en la diversidad de componentes de cada una de las dos grandes áreas que se mencionaron anteriormente, de allí que la directiva de la comunidad o la ONG de acompañamiento formativo, deberá buscar la mejor ayuda disponible, de tal manera que la capacitación sea la adecuada y además responda a las necesidades particulares de la comunidad.

(d) El momento de los servicios sociales. Este momento está vinculado al anterior, al menos en lo referente a la capacitación en el área social. Es común que las comunidades se vean en la necesidad de crear sus propios sistemas de salud y educación, debido a que el abandono gubernamental o la distante localización de las comunidades frena la llegada de personal técnico, el cual generalmente posee hábitos de vida urbanos. En cuanto a los otros servicios no gratuitos, es muy poco lo que los organismos no gubernamentales pueden hacer para satisfacerlos, de allí que su labor se limite a apoyar los esfuerzos de las comunidades frente a los gobiernos. Aunque de manera excepcional han colaborado, inclusive, con la instalación de plantas generadoras de energía eléctrica, es más económico conseguir la conexión a la red nacional.

(e) El momento del adiós. El mejor organismo no gubernamental es aquel que desde el primer día de trabajo con una comunidad está pensando en el momento de partir, ya que ello lo llevará a evitar las relaciones de dependencia de parte de la comunidad y estimulará la participación, la iniciativa, el respeto, la autoestima, la responsabilidad, etc. entre la población de la comunidad con que trabaja. De esta manera, las comunidades podrán mantener su actividad aun cuando ya no se cuente con la colaboración de ninguna ONG. Pero también es de

7. Para un mayor desarrollo de esta temática, consúltese Aquiles Montoya, La nueva economía popular: una aproximación teórica, UCA Editores, cap. 4, 1993. 
suma importancia el tipo de actividad económica que se haya propiciado en las comunidades para que éstas puedan sobrevivir al no contar con la ayuda solidaria así, por ejemplo, si lo que producen es demandado por los mismos integrantes de las comunidades se genera un dinamismo interno, el cual posibilitará que se mantenga siempre la actividad económica. En otras palabras, se plantea que una parte significativa de la producción de las comunidades debe buscar satisfacer aquellas necesidades propias de los integrantes de las comunidades.

\section{Cómo preservar al nuevo sector social}

A fin de que las nuevas comunidades se mantengan siempre activas y funcionando, es preciso que se establezca una serie de condiciones las cuales debieron desarrollarse hace algún tiempo bajo la denominación de "premisas de la nueva economía popular". En la actualidad, éstas todavía poseen un valor teórico de cara a hacer efectiva esta propuesta para abatir la pobreza, ya que la nueva economía popular poseía un componente antipobreza, razón por la cual se citarán con algunos pequeños cambios que se presentarán entre paréntesis.

(a) La generación de un excedente neto por parte de cualquier unidad económica. La razón es simple y obvia: la generación del excedente neto posibilita la reproducción en escala ampliada $y$ al hacerlo se torna posible

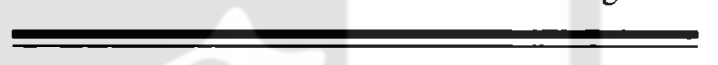

el aporte de los organismos no gubernamentales es de suma trascendencia, ya que ha sido por medio de su colaboración y apoyo que muchas comunidades se encuentran en condiciones de vida y trabajo muy superiores a como era su realidad en el pasado. cumplir los objetivos primarios de la estrategia. Estos son: la generación de nuevos puestos de trabajo, incremento en los niveles de ingresos y satisfacción de las necesidades sociales de sus miembros. Esto es de suma importancia ya que de no ser así no tendría ninguna viabilidad futura y tampoco razón de ser. Una estrategia económicosocial que sea incapaz de generar beneficios sociales no es una estrategia económica ( $y$ social).

Adicionalmente es preciso señalar que cuando haya excedente, su mayor proporción, si no su totalidad, debe destinarse a la reinversión más que a su consumo, ya que ello posibilitará un ritmo de crecimiento más rápido de las unidades económi- cas, lo cual traerá mayores ventajas a futuro para los integrantes de la comunidad.

(b) La efíciencia de la gestión económica, la cual se presenta como un presupuesto para la generación del excedente neto. En el ámbito de la producción ello implicaría la generación de una mayor cantidad de valores de uso con' los menores costos posibles, esto es, una optimización de los recursos. Ciertamente, esto no significa, como en la producción capitalista, comprimir las remuneraciones a los trabajadores. La eficiencia en la actividad económica está vinculada al empleo de las técnicas apropiadas conforme a la disponibilidad de recursos humanos y materiales; a la capacitación formal y tecnoadministrativo, así como a la obtención y manejo de recursos financieros y de las necesarias técnicas de comercialización. Además, cuidar los controles de calidad de los productos y servicios, porque como diría Marx: "las mercancías para realizarse como valores de uso deben primero realizarse como valores y para realizarse como valores deben acreditarse como valores de uso".

De manera general es preciso señalar que en cuanto a la eficiencia económica se refiere, las unidades económicas (de las comunidades) deben operar como auténticas empresas aunque lo sean de carácter autogestionario. El ser una empresa autogestionaria no puede ni debe ser excusa para la ineficiencia o para el despilfarro de los ingresos; el lujo y el despilfarro son los gasios de representación del capital, pero las nuevas cotmunidades no tienen por qué emular tales práclicas de un sistema que le es ajeno.

(c) La integración ínter e intrasectorial se presenta como otra premisa básica (para la preservación de la actividades económicas de las comunidades), lo cual ciertamente no implica pretensiones de autarquía, pero es obvio que cuanto más integradas se encuentren las diferentes unidades (comunitarias), mayor posibilidad tendrá ésta de lograr un crecimiento autogenerado y dinámico. La razón de ello radica en que en la medida en que las unidades económicas se incrementen y experimenten un mayor desarrollo, los ingresos dis- 
ponibles de sus miembros aumentarán. Esto a su vez generaría un incremento en la demanda de bienes y/o servicios de consumo, lo cual provocaría en las unidades económicas una mayor demanda de medios de producción, situación que se traduciría en un incremento de la producción de tales productos y así sucesivamente.

Como se podrá considerar en lo antes señalado, el dinamismo (de la estrategia económica) radica en sí misma, lo cual asegura un crecimiento sostenido y sostenible en el tiempo. Ahora bien, se señalaba que con la estrategia no se pretende la autarquía económica, lo cual implica que así como no se buscará autoabastecerse tampoco estará cerrada a la realización de sus mercancías en el sector capitalista. Ello se presenta como un medio para lograr un mejor funcionamiento y no como un fin en sí mismo, ya que de lo contrario se estaría trasladando el motor de su crecimiento hacia afuera de sí misma y perdería su dinámica propia.

Sin embargo, no sería posible lograr tal integración si se hace a un lado la asignación de recursos al mercado, por lo que, al menos en su primera fase de desarrollo, la propuesta presenta la necesidad de contar con algunas instancias de coordinación y planificación -que constituyen otras premisas básicas.

(d) La coordinación debe establecerse entre todas aquellas organizaciones que de una u otra manera buscan promover proyectos económicos entre los sectores populares. Este hecho evitaría el desperdicio de esfuerzos y recursos y a su vez posibilitaría la generación de los diversos eslabones necesarios para la integración de las diferentes unidades económicas (que conforman el nuevo sector social). Así como entre todas aquellas empresas existentes bajo la forma de cconomía popular que presentan grandes potencialidades para su transformación en elementos integrantes (del nuevo sector).

Para comprender la importancia y necesidad de la coordinación basta con pensar en la cantidad de instituciones gubernamentales y organismos no guhernamentales involucrados con los sectores populares que si no realizan un esfuerzo coordinado podrían, incluso, entorpecer sus propios trabajos, además de imposibilitar cualquier esfuerzo planificador.

(e) La planificación, por otra parte, se presenta como el elemento complementario de la coordinación en tanto no sólo posibilitaría la integración (del nuevo sector sector), sino que concretizaría los esfuerzos de coordinación. También la planificación presenta la ventaja de posibilitar un crecimiento armónico y proporcionado de las diferentes ramas (del sector), evitando los costos de efectuar correcciones a posteriori como los que posibilita realizar el mercado.

La planificación, tanto en el interior de las unidades económicas (del sector) como un todo, es un instrumento económico que es preciso revalorizar a fin de obtener con el mismo la máxima eficiencia social posible. Lo cierto es que no se presenta como un sustituto para el mercado, sino como un corrector o regulador del mismo, en tal sentido, la planificación no es incompatible con el mercado sino complementaria. La planificación vendría a ser como el lazarillo ante la ceguera del mercado, ciertamente no posibilita ver pero si evita caer en cualquier agujero.

(f) Finalmente, otra premisa básica (de la estrategia) es la organización, tanto a nivel de las unidades económicas (de las ramas) de las comunidades, como de todo el sector. Tan importante y necesaria es la organización a nivel de una unidad productiva - (la empresa), por ejemplo- como a nivel de las diferentes comunidades del nuevo sector social. Tal organización es de suma importan-

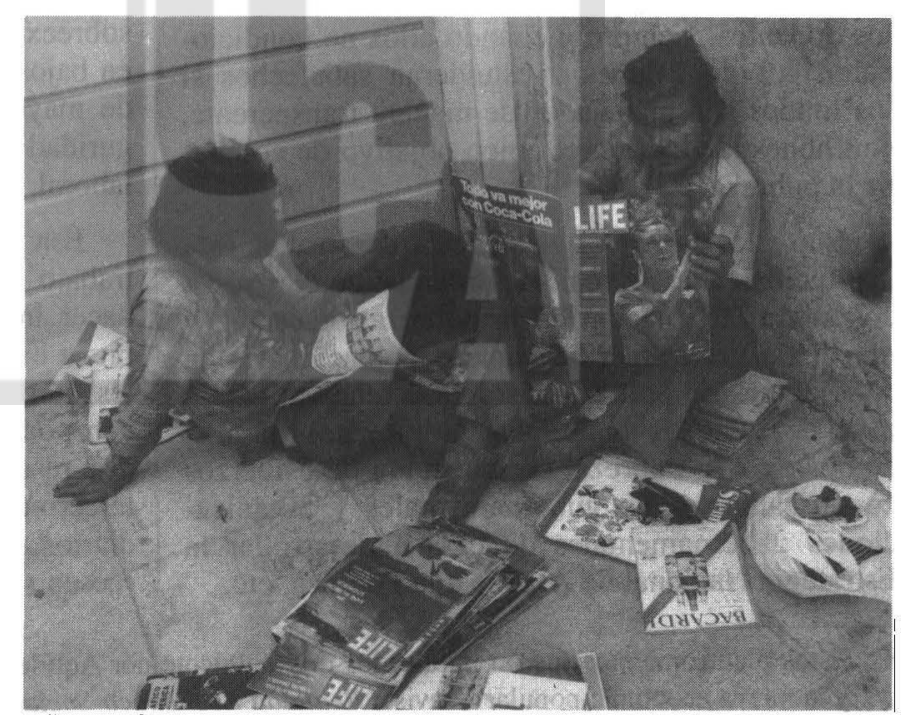


cia para hacer posible las anteriores premisas, así como para transformar la debilidad individual que presentan las unidades económicas en fortaleza.

Por otra parte, sólo a través de la organización es posible ir avanzando hacia la novedad en las formas económicas, acordes con las necesidades de los diferentes agentes económicos. La organización, al potenciar al individuo, crea las bases para asimilar las ventajas de las formas asociativas en materia económica, en tanto que la fortaleza del individuo no proviene de su individualidad sino de su unidad, con lo cual el sujeto colectivo va desplazando al sujeto individual y el nosotros va reemplazando al yo. No se niega al individuo pero sí se cuestiona al individualismo por su carácter dispersor y debilitante".

\section{Institucionalidad requerida para viabilizar la propuesta}

Generalmente cuando se habla de instituciones existe una especie de acción refleja que induce a pensar en la burocracia; sin embargo, a fin de facilitar, promover y llevar a cabo la estrategia antipobreza, sería conveniente pensar en la creación de una institución que funcione como una corporación de utilidad pública; creada con recursos estatales pero sin ninguna dependencia estatal; gobernada por un directorio que estuviera conformado por personas representativas de distintos sectores sociales y con capacidad e iniciativa para captar recursos provenientes tanto de fuentes nacionales como internacionales.

No habría ninguna discriminación en cuanto a los donantes, siempre y cuando ellos no condicionaran sus donaciones y estuvieran satisfechos si los fondos son manejados de manera transparente, con honestidad y con el único objetivo de combatir la pobreza.

Entre las labores que debería desarrollar esta institución estarían: realización anual de diagnósticos sobre la situación de la pobreza; detección y ubicación geográfica de núcleos poblacionales en condiciones de pobreza absoluta y relativa; captación de recursos materiales y humanos para el combate de la pobreza; coordinación de esfuerzos con organismos no gubernamentales y organizaciones gubernamentales de cara a desarrollar la Estrategia Nacional de Ataque a la Pobreza, etc.
Será de suma importancia que en el núcleo director de la institución siempre existan representantes de los pobres, tanto de origen rural como urbano. La legitimidad de la corporación estará determinada por el grado de aceptación que tenga entre los pobres, la cual facilitará o entorpecerá la eficacia de su labor en la lucha antipobreza.

\section{Reflexiones finales}

Seguramente se está de acuerdo en que la consecución del fin propuesto exige una labor bastante compleja aunque la fórmula parece sencilla: generar empleo que procure ingresos necesarios y suficientes para la satisfacción de las necesidades materiales y espirituales. Es imposible realizarlo si previamente no se procura una dotación de activos a los pobres. Pero para que estos generen ingresos se exige cierta capacitación a las personas, etc. Lo que se desea destacar es que si bien la generación de empleo parece una cuestión sencilla, no lo es, e inclusive, es todavía más complicado conservar el empleo generado.

La generación de un nuevo puesto de trabajo en una empresa capitalista de tecnología intermedia exige de cantidades enormes de inversión, ésta es la razón por la que los gobiernos cautivan, protegen y defienden a las maquilas, a pesar de su precariedad y volatilidad. Esta modalidad de empresas constituye una degeneración de las empresas capitalistas típicas o, si se prefiere, es la modalidad de empresas creadas a fin de evadir las conquistas sociales logradas por los trabajadores en el primer mundo. Por ende, en ellas prevalece la sobreexplotación del trabajo, lo cual se manifiesta en bajos salarios, jornadas de trabajo más largas y de mayor intensidad, pésimas condiciones de seguridad y salubridad y una increible inestabilidad laboral.

Esa dificultad de generar nuevos puestos de trabajo a partir de la inversión capitalista debería hacer interesante y atractiva la propuesta antipobreza bajo condiciones no capitalistas, en las cuales aún es posible generar ocupación e ingresos con poca inversión. Además, su conservación podría resultar relativamente sencilla si los gobiernos tercermundistas fuesen realmente gobiernos subsidiarios, y los poderosos países del primer mundo fuesen solidarios con los del tercer mundo.

8. Estos planteamientos fueron publicados originalmente por Aquiles Montoya, "El sector agropecuario reformado y la nueva economía popular", revista Realidad Económico-Social, mayo-junio, 1992, pp. 262 y ss. 
Ciertamente, mucho de lo que se ha expuesto no es más que un conjunto de obviedades; sin embargo, con ellas se ha pretendido delinear un camino hacia la no pobreza y, de alguna manera, contribuir a animar a quienes se dedican a lidiar con ella y manifestarles que es posible abatir la pobreza si se marcha por la ruta correcta. Pero también comunicarles a los políticos y gobernantes: "de las decisiones de ustedes depende en gran parte que se ataque a la pobreza de manera efectiva y efi- ciente. También gritarles a los ricos del primer mundo que si no hay solidaridad económica y material con el tercer mundo hoy, mañana pudiera ser que ustedes despierten en la pesadilla real que es nuestro cotidiano vivir y ya no encuentren donde esconder sus lamentos".

Por las razones que sean, hay que trabajar para abatir la pobreza... Es posible hacerlo y les ahorraríamos a los pobres tanta pero tanta crueldad. 